\title{
KUALITAS JASA DAN HUBUNGANNYA DENGAN LOYALITAS SERTA KOMITMEN KONSUMEN: STUDI PADA PELANGGAN SALON KECANTIKAN
}

\author{
Hj. Farida Jasfar \\ Fakultas Ekonomi \\ Universitas Trisakti
}

\begin{abstract}
The purpose of the study was to determine whether consumer loyalty mediates between service quality and consumer commitment in the beauty salon industry. It was also to determine whether these relationships difference between beauty salon in shopping centers and beauty salon in community residences.

A theoretical framework was developed to test the positive relationships among the study constructs. The study utilized service quality developed by Fullerton and Taylor (2000); Parasuraman, Zeithaml and Berry (1994), consumer loyalty developed by Unclesand Laurent (1997); Fullerton and Taylor (2000), and consumer commitment developed by Morgan and Hunt (1994); Fullerton and Taylor (2000).

The degree of customer loyalty, commitment, and service quality was measured by using the Likert scale based on 238 valid questionnaire respondents (59,5\% from 400 dispersed questionnaires).

An analysis of the data revealed two major findings: First; there is a positive relationship between service quality and consumer loyalty, affective commitment, and continuum commitment. Second; consumer loyalty is the mediating variable of the relationship between service quality and consumer commitment both in beauty salons in shopping centers and beauty salons located in community residences.

The results of this study have important implications for practicing managers of beauty salons and their understanding of the relationship between service quality, consumer loyalty and consumer commitment.
\end{abstract}

Key words: services quality, loyalty, and commitment.

\section{LATAR BELAKANG PENELITIAN}

Pemasaran jasa telah menjadi kajian dalam penelitian pemasaran yang cukup menantang dan semakin menarik untuk diteliti lebih mendalam. Salah satu yang paling intensif yang selalu dilakukan para peneliti adalah pengujian kualitas jasa dari segi kontruk (laccobucci, 1998). Demikian pula halnya dengan studi tentang hubungan yang positif antara kualitas jasa dengan komitmen dan loyalitas konsumen.

Meskipun merupakan konsep lama dalam pemasaran, namun untuk ukuran pada tingkat empirik, konsep atau konstruk loyalitas konsumen cukup beragam penggunaannya. Misalnya penelitian yang dilakukan oleh Cronin \& Taylor (1992), Rust, et al., (1995), Zeithaml, et al., (1996); dan Gabarino \& Johnson (1999), menemukan adanya hubungan antara kualitas jasa dengan loyalitas konsumen dilihat dari segi kecenderungan berperilaku (behavioral intentions). Sementara Fullerton and Taylor (2000) melihat 
loyalitas dalam hubungannya dengan kualitas jasa yang tergambar dalam sikap konsumen, seperti: membeli kembali (repurchase behavior) dan sensitifitas terhadap harga (price sensitivity). Pada sisi lain komitmen sebagai variabel hasil (outcome) atau sebagai variabel mediator yang menentukan dalam berbagai rujukan pemasaran relasional (relationship marketing) telah diakui dan tidak dapat diabaikan untuk keberhasilan suatu pemasaran jasa (Gundlach, et al (1995); Morgan \& Hunt, 1994).

Penelitian paling mutakhir yang dilakukan oleh Fullerton and Taylor (2000) mencoba membuktikan hubungan antara kualitas jasa, komitmen dan loyalitas konsumen. Hasil penelitiannya membuktikan bahwa hubungan antara kualitas jasa dan komitmen konsumen akan lebih baik bila melalui loyalitas. Mereka membedakan konsep komitmen kedalam tiga kategori yaitu pertama: komitmen afeksi yaitu komitmen yang merujuk pada pembagian nilai (shared values) dan kemurahan hati (benevolence), kedua: komitmen kontinum yaitu komitmen yang merujuk kepada pengorbanan dan ketergantungan, ketiga: komitmen normative yaitu komitmen yang merujuk kepada konstruk menyeluruh yang menjadi penyebab tumbuhnya rasa berbagi tanggung jawab. Fullerton dan Taylor (2000) selanjutnya membedakan loyalitas atas tiga kategori pula yaitu pertama: repurchase intentions yaitu keinginan yang kuat dari konsumen untuk membeli kembali jasa tertentu, kedua: advocacy intentions, dan ketiga: paymore yaitu kesediaan untuk membayar lebih.

Berbagai penelitian yang telah kami lakukan mengenai konsep komitmen, loyalitas dalam hubungannya dengan kualitas jasa pun secara empirik menunjukkan hasil yang beragam (Jasfar, 1998; 1999, 2000). Untuk itu peneliti tertarik pula untuk melakukan pengujian ulang dari segi pengukuran instrumen kualitas jasa, komitmen dan loyalitas konsumen pada industri jasa lainnya yaitu salon kecantikan. Pengujian pada tingkat pengukuran ini perlu dilakukan, karena adanya perbedaan dari segi karakteristik konsumen yang berbeda untuk masing-masing negara, termasuk pula perbedaan jasa yang ditawarkan.

Selain itu pula, perbedaan latar belakang budaya, sosial. dan tingkat ekonomi konsumen akan memberikan kecenderungan perilaku yang berbeda. Bukanlah hal yang terlalu aneh bila indikator kualitas jasa, komitmen dan loyalitas antara satu kelompok konsumen dengan kelompok konsumen lainnya akan bisa memberikan hasil yang berbeda.

Berdasarkan paparan tersebut, maka peneliti akan lebih memfokuskan peranan kualitas jasa, loyalitas dan komitmen dalam pemasaran jasa pada salon kecantikan yang berada di sekitar Jakarta, Bogor, Depok, Bekasi, Tangerang dan Bandung, secara khusus yang terletak pada pusat perbelanjaan modern (mal) yang berada di kota-kota besar tersebut. 


\section{PERUMUSAN MASALAH}

Masalah penelitian yang pokok adalah bagaimana peranan loyalitas sebagai variable mediator antara kualitas jasa dengan komitmen pelanggan pada salon kecantikan di Jakarta, Bogor, Depok, Bekasi dan Tangerang. Secara lebih spesifik, dapat dirumuskan masalah (pertanyaan) penelitian sebagai berikut: (1). Bagaimana hubungan antara variabel kualitas jasa, loyalitas, dan komitmen?; (2). Apakah terdapat perbedaan kualitas jasa, loyalitas dan komitmen antara salon kecantikan yang berada di pertokoan modern (Mall) dengan salon kecantikan yang berada di daerah permukiman penduduk?; (3). Bagaimana peranan loyalitas sebagai mediator antara kualitas jasa dengan komitmen?

\section{STUDI PUSTAKA}

\section{Kualitas Jasa}

Jasa, secara umum diartikan sebagai: "any act or performance that one party can offer to another that is essentially intangible, and does not result in the ownership of anything" (Kotler, 1998, p.467). Secara spesifik Gronroos (1990, p.25) mendefinisikan jasa sebagai: "an activity or series of activities of more or less intangible nature that normally, but not necessarily, take place in interactions between the customer and service employees and/or physical resources or goods and or systems of the service provide, which are provided as solutions to customer problem".

Jasa tidak dapat dilihat, diraba, dicium, didengar, dirasakan seperti halnya produk nyata, sehingga penilaian terhadap kualitas jasa berbeda dengan penilaian terhadap produk. Karena jasa mempunyai karakteristik tertentu seperti yang telah dijelaskan, maka bagaimana konsumen menilai jasa yang ditawarkan (consumer perceived service quality) menentukan kualitas jasa (Zeithaml, 1981). Bitner and Hubert (1994, p.77) mendefinisikan kualitas jasa sebagai: "the consumer's over all impression of the relative inferiority/ superiority of the organization and its services". Jadi kualitas jasa ditentukan atas bagaimana tanggapan konsumen terhadap jasa, yang berarti hanya bisa diketahui setelah konsumen pernah mencoba atau mempunyai pengalaman dengan jasa tersebut.

Dalam bidang kualitas jasa, Parasuraman, et al, (1994), mengembangkan skema pengukuran kualitas jasa dari sejumlah dimensi. Pengukuran yang mereka kembangkan dikenal dengan terminologi Service Quality (SERVQUAL), termasuk dalam uraiannya mengemukakan tentang perbedaan antara harapan (expectation) dan kinerja (performance) dari sejumlah criteria jasa yang saat ini secara luas digunakan untuk mengukur 
kualitas jasa. Beberapa peneliti mengkritisi dimensi-dimensi kualitas jasa sebagaimana yang dikemukakan oleh Parasuraman, et al (1994) bahwa dimensi kualitas jasa tersebut tidak bisa digene-ralisasikan dalam konteks penggunaannya antar lintas sector jasa (Babakus \& Boller (1992); Bolton \& Drew (1991); Brown, et al, (1993); Carman (1990); Cronin \& Taylor (1994); Freeman \& Dart (1993). Sementara peneliti-peneliti lainnya gagal melakukan penelitian replikasi dari dimensi asli Parasuraman, et al, (1994) atau instrumennya gagal dimodifikasi untuk disesuaikan dengan studi yang lebih spesifik (Lapierre, 1996).

Pendapat yang agak berbeda dikemukakan oleh lacobbucci (1998) dan Eagly \& Chaiken (1993) yang mengemukakan mengenai kualitas jasa yang melihatnya lebih dekat kepada sikap karena menyangkut penilaian menyeluruh atas pelayanan yang diterima oleh pelanggan. Penilaian ini berdasarkan pada berbagai penelitian yang dilakukan, terutama hubungannya dengan kecenderungan berperilaku (behavior intention) seperti re-purchace intention, switching intention, advokasi dan price sensitivity. Beranjak dari pandangan tersebut Fullerton dan Taylor (2000) sependapat bahwa kualitas jasa merupakan salah satu bentuk sikap dari konsumen, dan menolak melihat kualitas jasa hanya sekedar kesenjangan atas harapan dan kinerja sebagaimana dikemukakan oleh Parasuraman, et al, (1994).

\section{Loyalitas Konsumen}

Konsep mengenai loyalitas merupakan suatu konsep lama dalam kajian pemasaran dan selalu berkembang dengan berbagai variannya. Loyalitas adalah sebagai salah satu bentuk dari sikap seperti kecenderungan berperilaku (behavioral intention) dan propensity (Dick \& Basu, 1994; Uncles \& Laurent, 1997), dan ada pula yang menyebutkan sebagai repurchase behavior (Sharp \& Sharp, 1997). Dalam studi lain, loyalitas dirumuskan sebagai perpaduan antara repurchace intention, advokasi, intention dan preferensi (Fornell et.al., 1996; Zeithmal, Berry dan Parsuraman, 1996). Sama halnya dengan peneliti peneliti diatas, Fullerton dan Taylor (2000) melihat loyalitas dalam hubungan antara kualitas jasa dengan sikap (perilaku) seperti re-purchase, advokacy dan price sensitivity. Penelitian tentang loyalitas dalam pemasaran jasa sering dikaitkan dengan tingkat kepercayaan konsumen (trust) dan tingkat komitmennya. Loyalitas bisa sebagai variable hasil/outcome (Morgan and Hunt (1994), bisa juga sebagai variable perantara/mediating variable (Fullerton and Taylor,2000).

\section{Komitmen}

Dalam pemasaran jasa, komitmen dirumuskan sebagai suatu bentuk perjanjian yang tersurat maupun tersirat untuk melanjutkan hubungan antar dua pihak atau lebih "implicit and or explicit pledge of 
relational continuity between exchange partners" (Dwyer, et al 1987, p. 19). Komitmen dalam konsep long term relationship, memegang peranan yang sangat penting karena hubungan jangka panjang paling banyak didasarkan kepada komitmen kedua belah pihak. Moorman, et al (1992,p.23), mendifinisikan commitment as: "an enduring desire to maintain a valued relationship". Definisi ini lebih menekankan pengertian komitment dari unsur perilaku sebagai upaya untuk mempertahankan dan menjaga hubungan jangka panjang antara kedua belah pihak agar hubungan ini lebih bernilai. Pengertian "value relationship" dikaitkan dengan suatu keyakinan bahwa tidak akan terjadi suatu komitmen, apabila salah satu pihak atau keduaduanya merasa bahwa hubungan itu tidak saling menguntungkan. Dengan perkataan lain komitmen berarti di dalamnya terdapat suatu hubungan yang berharga yang perlu dipertahankan terus, di mana masing-masing pihak bersedia bekerja sama untuk mempertahankan hubungan ini. Konsep ini dipertegas oleh oleh Morgan and Hunt (1994, p.23) yang menyatakan bahwa: "relationship commitment exist only when the relationship is considered important and a commited partner wants relationship to endure indefinitely and is willing to work at maintaining it". Akhirnya Berry dan Parasuraman yang sangat banyak meneliti tentang kualitas jasa dan hubungannya dengan komitmen menyatakan bahwa: "relationships are built on the foundation of mutual commitment" (1991, p.139). Mereka menekankan pentingnya komitmen dalam membangun suatu hubungan antara perusahaan dengan para pengguna jasa.

Dalam pengetahuan perilaku keorganisasian, komitmen dilihat sebagai konstruk yang menjadi pengikat antara pegawai dengan perusa-haan (Alen dan Meyer, 1990; Mathieu dan Zajac, 1990). Komitmen memainkan peranan yang signifikan dalam menjelaskan intensitas pegawai seperti berhenti dari pekerjaan (quitting) dan perilaku perilaku karyawan lainnya. Komitmen sebagai suatu konstruk yang multi-komponen, menurut Allen dan Meyer (1990) terdiri dari tiga unsur yaitu komitmen afeksi, komitmen berkelanjutan (kontinum) dan komitmen normatif. Selama ini umumnya komitmen lebih banyak dilihat dari segi afeksi. Namun untuk penelitian pemasaran relasional tidak cukup hanya melihat dari segi afeksi semata, karena menurut Fullerton dan Taylor (2000:6) konsumen memiliki sejumlah perasaan atas hubungan mereka dengan penyedia jasa (service provider) yang merefleksikan komitmen afeksi, komitmen berkelanjutan dan komitmen normatif.

Komitmen afeksi dalam pemasaran hubungan (relationship marketing) seperti yang dikemukakan oleh banyak penulis dibidang ini (Doney dan Cannon, 1997; Garbarino dan Johnson, 1999; Heide dan John; 1992; Morgan dan Hunt, 1994). merujuk pada pembagian nilai (share values), kepercayaan (beliefs), kemurahan hati (benevolence), dan hubungan baik 
(relationalisme.) Penggunaan komitmen afeksi dalam pemasaran relational (relationship marketing) mampu bertahan ketika mengindentifikasi seseorang dengan perasaan senangnya dan keikutsertaannya dalam suatu organisasi (Meyer dan Allen, 1990). Identifikasi ini menjadi sudut pandang yang cukup efektif dalam pemasaran relasional (Fournier dan Yao, 1998). Dengan demikian, konsumen sebaiknya dipandang dari segi komitmen afeksi oleh penyedia jasa ketika mereka mengekspresikan perasaannya kepada penyedia jasa.

Komitmen kontinum dalam pemasaran relasional berakar dari biaya peralihan (switching cost), pengorbanan (sacrifice), dan ketergantungan (dependence). Pendapat tersebut bersumber dari Bendapudi dan Berry (1997); Gundlach, Achrol dan Mentzer (1995), serta Heide dan John (1992). Dengan kata lain, pelanggan dapat melakukan komitmen dengan perusahaan jika mereka merasa pada akhir hubungan tersebut memang diperlukan adanya pengorbanan ekonomi maupun sosial.

Komitmen normatif bertahan dalam pemasaran relasional ketika pelanggan merasa sebagai bagian dari tanggung jawab perusahaan. Unsur komitmen ini dapat dijelaskan dari konsep timbal balik (reciprocity) dari Bagozi (1995), pembagian nilai (shared value) dari Fournier dan Yao (1998) serta legitimasi dari Handehman dan Arnold (1999). Unsur-unsur komitmen normatif tersebut merupakan konstruk menyeluruh yang menjadi peyebab tumbuhnya rasa berbagi tanggung jawab sebagai pendorong.

\section{KERANGKA PEMIKIRAN}

Gambar 1. Loyalitas sebagai Mediator antara Kualitas Jasa dan Komitmen

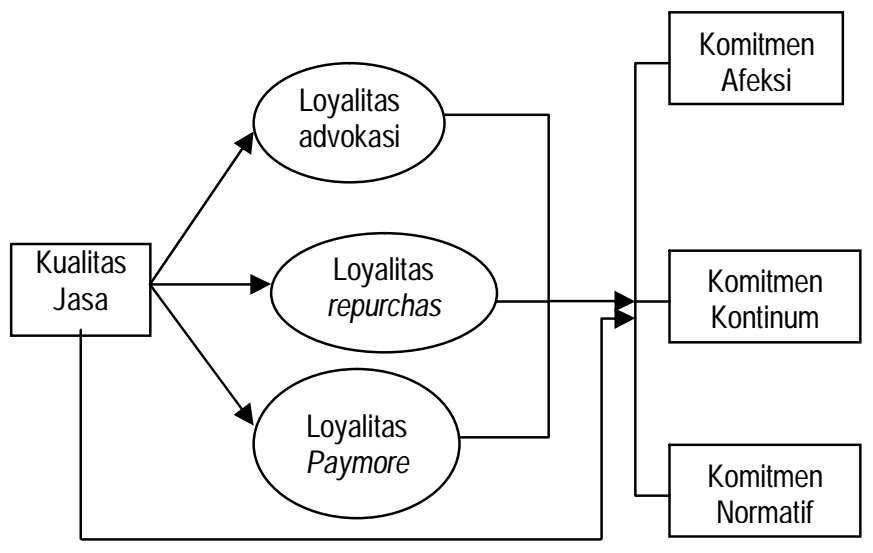




\section{HIPOTESIS}

Mengacu kepada hasil studi pustaka dan kerangka pemikiran di atas, maka disusunlah sejumlah hipotesis untuk menguji peranan loyalitas sebagai mediator antara kualitas jasa dan komitmen seperti di bawah ini.

- Hipotesis $1 \mathrm{~s} / \mathrm{d}$ 3: Ada pengaruh yang positif antara kualitas jasa dengan loyalitas "advokasi"; loyalitas "repurchase" (bersedia untuk membeli lagi) dan loyalitas "paymore" (bersedia untuk membayar lebih mahal).

- Hipotesis $4 \mathrm{~s} / \mathrm{d}$ 6: Ada pengaruh yang positif antara kualitas jasa dengan komitmen afeksi; komitmen kontinum dan komitmen normatif.

- Hipotesis $7 \mathrm{~s} / \mathrm{d}$ 9; Ada pengaruh yang positif antara loyalitas advokasi dengan komitmen afeksi; komitmen kontinum dan komitmen normatif.

- Hipotesis $11 \mathrm{~s} / \mathrm{d}$ 13; Ada pengaruh yang positif antara loyalitas "repurchase" dengan komitmen afeksi; komitmen kontinum dan komitmen normatif.

- Hipotesis $14 \mathrm{~s} / \mathrm{d}$ 15; Ada pengaruh yang positif antara loyalitas "paymore" dengan komitmen afeksi; komitmen kontinum dan komitmen normatif.

- Hipotesis 16: Ada perbedaan kualitas jasa, loyalitas dan komitmen pada kelompok gerai 1 dan kelompok gerai 2 salon kecantikan.

- Hipotesis 17: Loyalitas memiliki pengaruh yang positif sebagai mediator antara kualitas jasa dan komitmen.

\section{METODOLOGI PENELITIAN}

Rancangan penelitian yang digunakan adalah kausal karena penelitian mengkaji satu variabel atau lebih yang menyebabkan atau menjadi determinan terhadap variabel lainnya (Aaker et.al., 1998: 75). Untuk skala pengukuran dipergunakan Skala Likert berupa ekspresi pernyataan atau pertanyaan dari sangat tidak setuju sampai dengan sangat setuju dengan skor angka 1 sampai dengan 7. Sumber indikator dari dimensi-dimensi tersebut merupakan adopsi dari berbagai penelitian mengenai kualitas jasa, komitmen, dan behavior intention yang dilakukan oleh Joze Lapiere (1996). Zeithmal, et al (1996), Allen dan Meyer (1990, serta Fullerton dan Taylor (2000).

Metoda penarikan sampling dengan memakai metoda non probabilita yaitu convenience sample dari pelanggan salon yang ada di Jakarta, Bogor, Tangerang, Depok, Bekasi dan Bandung pada pusat perbelanjaan modern (mall) yang berada dienam kota tersebut. Sementara data primer bersumber dari kuestioner yang disebarkan kepada para pelanggan salon kecantikan di Jakarta, Bogor, Tangerang, Depok, Bekasi dan Bandung. 
Terakhir mengenai metoda analisis data, digunakan analisis statistik deskriptif, untuk melihat tiga karakteristik sampel yang terjaring dalam penelitian ini. Analisis korelasi dipakai untuk pengujian hipotesis hubungan antara variabel kualitas jasa, loyalitas, dan komitmen. Analisis rata-rata untuk pengujian rata-rata antara kelompok gerai 1 dan gerai 2 salon kecantikan untuk melihat apakah ada perbedaan atau tidak antara kedua kelompok gerai tersebut. Dan, linear structural relationship (LISREL) atau juga disebut SEM (Structural Equation Modeling) digunakan untuk menguji loyalitas sebagai variabel mediator antara kualitas jasa dan komitmen.

\section{ANALISA DAN PEMBAHASAN}

\section{Deskripsi Objek Penelitian}

Pelanggan salon kecantikan yang menjadi responden dalam penelitian ini cukup beragam dan tersebar. Keragaman responden adalah terjaring pada salon-salon kecantikan yang berada pada pusat-pusat perbelanjaan modern sampai pada tingkat lingkungan perumahan, dan dipinggiran kota (sub-urban). Ketersebaran responden tidak hanya pada salon kecantikan yang berada di Jakarta tetapi juga Bogor, Tangerang, Depok, Bekasi dan bahkan hingga Bandung.

Salon kecantikan pun dapat dibagi dalam dua kelompok yaitu salon kecantikan yang telah memiliki nama besar dalam dunia busana atau mode (fashion) seperti Peter Saerang, Johny Andrean, Yopy Andrean dan Rudi Hadisuwarno. Kedua, salon kecantikan yang berada pada daerah sekitar pemukiman baik yang berada di Jakarta maupun kota-kota lainnya yang telah disebutkan di atas.

Dari data tersebut terlihat bahwa gerai (outlet) salon kecantikan Johny Andrean adalah salon kecantikan yang paling ekspansif dengan jumlah gerai yang tersebar secara merata baik di pusat perbelanjaan yang berada di Jakarta maupun kota-kota besar lainnya. Keberhasilan Johny Andrean Salon tidak terlepas dari strategi pemasaran dengan memperluas jaringan (channel distribution) dengan pendekatan "franchise organizations". Pada urutan berikutnya bertengger salon kecantikan milik Rudi Hadisuwarno yang juga memiliki strategi membuka gerai pada pusat bisnis (central business districts), pusat perbelanjaan yang cukup besar (regional shopping centers), pusat perbelanjaan komunitas (community shopping centers). Demikian pula dengan Peter Saerang Salon dan Yopie Andrean Salon. Selain keempat nama "besar" tersebut di atas terdapat pula salon-salon kecantikan tingkat menengah yang memiliki salon kecantikan pada pusat perbelanjaan seperti Lutuye dan Maxi Salon. Selebihnya adalah salon kecantikan yang memiliki gerai yang termasuk dalam kategori shopping strips dan di daerah perumahan 
atau pemukiman penduduk. Data selengkapnya mengenai salon kecantikan yang terjaring dan jumlah respondennya diringkas dalam Tabel 1.

Tabel 1.

Daftar Nama Salon Kecantikan

\begin{tabular}{|c|c|c|c|c|c|}
\hline \multirow[t]{2}{*}{ No } & \multirow{2}{*}{$\begin{array}{l}\text { Nama Salon } \\
\text { (Lokasi) }\end{array}$} & \multicolumn{2}{|c|}{ Responden } & \multirow{2}{*}{ Gerai } & \multirow{2}{*}{ Kota } \\
\hline & & \# & $\%$ & & \\
\hline 1. & Johny Andrean & 33 & 13,06 & $\begin{array}{l}\text { Mal dan pusat perbe- } \\
\text { lanjaan }\end{array}$ & Jabotabek \\
\hline 2. & Rudi Hadisuwarno & 18 & 7,56 & $\begin{array}{l}\text { Mal dan pusat perbe- } \\
\text { lanjaan }\end{array}$ & Jabotabek \\
\hline 3. & Peter Saerang & 15 & 6,30 & $\begin{array}{l}\text { Mal dan pusat perbe- } \\
\text { lanjaan }\end{array}$ & Jabotabek \\
\hline 4. & Yopie Andrean & 6 & 2,52 & $\begin{array}{l}\text { Mal dan pusat perbe- } \\
\text { lanjaan }\end{array}$ & Jabotabek \\
\hline 5. & Lutuye & 16 & 6,72 & Tebet Utara Dalam No.11 & Jakarta Selatan \\
\hline 6. & Maxi & 7 & 2,94 & Pusat perbelanjaan & Jak. Sel. \& Utara \\
\hline 7. & Nina Richie & 5 & 2,10 & Pusat perbelanjaan & Bekasi \& Jaksel \\
\hline 8. & La Vancy & 4 & 1,68 & Pusat perbelanjaan & Jakarta Selatan \\
\hline 9. & Michiko & 6 & 2,52 & Pusat perbelanjaan & Jakarta Timur \\
\hline 10. & Jakarta Utara & 2 & 0,84 & Shopping strips & \\
\hline 11. & Jakarta Selatan & 25 & 10,50 & Shopping strips & \\
\hline 12. & Jakarta Pusat & 13 & 5,46 & Shopping strips & \\
\hline 13. & Jakarta Timur & 20 & 8,40 & Shopping strips & \\
\hline 14. & Jakarta Barat & 38 & 15,97 & Shopping strips & \\
\hline 15. & Bekasi & 12 & 5,04 & Shopping strips & \\
\hline 16. & Tangerang & 9 & 3,78 & Shopping strips & \\
\hline 17. & Bogor & 1 & 0,42 & Shopping strips & \\
\hline 18. & Bandung & 8 & 3,36 & Shopping strips & \\
\hline
\end{tabular}

Sumber : Diolah dari primer penelitian.

Berikutnya adalah uraian tentang karakteristik responden yang diringkas dalam Tabel 2. dengan indikator ciri-ciri seperti jenis kelamin, usia, pendapatan rata-rata per bulan, status perkawinan, etnis, tingkat pendidikan, pekerjaan dan lama menjadi pelanggan salon kecantikan.

Responden yang menjadi sampel penelitian dari segi jenis kelamin yang terbanyak adalah perempuan (73,95\%). Hal ini sejalan dengan jasa inti (core senvice) salon kecantikan adalah untuk menambah rasa percaya diri para pelanggan yang umumnya adalah kaum perempuan. 
Tabel 2.

Karakteristik Sampel Pelanggan Salon Kecantikan

\begin{tabular}{|c|c|c|}
\hline Profil Pelanggan Domestik & Jumlah & $\%$ \\
\hline $\begin{array}{l}\text { 1. Jenis Kelamin } \\
\text { a. Pria } \\
\text { b. Perempuan }\end{array}$ & $\begin{array}{l}62 \\
176\end{array}$ & $\begin{array}{l}26.05 \\
73.95 \\
\end{array}$ \\
\hline $\begin{array}{l}\text { 2. Usia (Tahun) } \\
\text { a. }<20 \\
\text { b. } 21-30 \\
\text { c. } 31-49 \\
\text { d. } 41-50 \\
\text { e. }>50\end{array}$ & $\begin{array}{l}32 \\
153 \\
51 \\
23 \\
4 \\
\end{array}$ & $\begin{array}{l}13.44 \\
64.27 \\
21.42 \\
9.66 \\
1.68 \\
\end{array}$ \\
\hline $\begin{array}{l}\text { 3. Pendapatan rata-rata per bulan (rupiah) } \\
\text { a. }<1.500 .000 \\
\text { b. } 1.500 .000-2.000 .000 .- \\
\text { c. } 2.000 .000-2.500 .000 .- \\
\text { d. } 2.500 .000-3.000 .000 .- \\
\text { e. } 3.000 .000-3.500 .000 .- \\
\text { f. } 3.500 .000-4.000 .000 .- \\
\text { e. }>4.000 .000 \text {-- }\end{array}$ & $\begin{array}{l}140 \\
37 \\
18 \\
12 \\
11 \\
7 \\
13\end{array}$ & $\begin{array}{l}58.82 \\
15.54 \\
7.56 \\
5.04 \\
4.62 \\
2.94 \\
5.46\end{array}$ \\
\hline $\begin{array}{l}\text { 4. Status sipil } \\
\text { a. Bujangan } \\
\text { b. Kawin dengan } 1 \text { anak } \\
\text { c. Kawin dengan } 2 \text { anak } \\
\text { d. Kawin dengan }>2 \text { anak } \\
\text { d. Kawin tanpa anak }\end{array}$ & $\begin{array}{l}165 \\
20 \\
25 \\
17 \\
10\end{array}$ & $\begin{array}{l}69.32 \\
8.40 \\
10.50 \\
7.14 \\
4.20\end{array}$ \\
\hline $\begin{array}{l}\text { e. Cerai } \\
\text { 5. Pendidikan }\end{array}$ & 1 & 0.42 \\
\hline $\begin{array}{l}\text { a. } \leq \text { SMP atau sederajat } \\
\text { b. SMU atau sederajat } \\
\text { c. D3 atau sederajat } \\
\text { d. } \text { S }_{1} \text { atau sederajat }\end{array}$ & $\begin{array}{l}4 \\
111 \\
57 \\
66 \\
\end{array}$ & $\begin{array}{l}1.68 \\
46.63 \\
23.95 \\
27.73 \\
\end{array}$ \\
\hline $\begin{array}{l}\text { 6. Pekerjaan } \\
\text { a. Manajer } \\
\text { b. PNS } \\
\text { c. Teknisi } \\
\text { d. Pengusaha Swasta } \\
\text { e. Guru/Dosen } \\
\text { f. Pemasar (Marketer) } \\
\text { g. Pelajar/Mahasiswa } \\
\text { h. Ibu Rumah Tangga } \\
\text { h. Lain-lain } \\
\end{array}$ & $\begin{array}{l}19 \\
7 \\
2 \\
23 \\
4 \\
17 \\
111 \\
24 \\
31 \\
\end{array}$ & $\begin{array}{l}7.98 \\
2.94 \\
0.84 \\
9.66 \\
1.68 \\
7.14 \\
46.63 \\
10.08 \\
13.02 \\
\end{array}$ \\
\hline $\begin{array}{l}\text { 7. Lama menjadi pelanggan } \\
\text { a. }<1 \text { bulan } \\
\text { b. } 1-3 \text { bulan } \\
\text { c. } 4-6 \text { bulan } \\
\text { d. }>7 \text { bulan }\end{array}$ & $\begin{array}{l}26 \\
39 \\
42 \\
131 \\
\end{array}$ & $\begin{array}{l}10.92 \\
16.38 \\
17.64 \\
55.04 \\
\end{array}$ \\
\hline
\end{tabular}

Sumber: Diolah dari data primer penelitian.

Untuk usia responden yang terbesar adalah yang berumur antara 21 sampai dengan 30 tahun yaitu $64,27 \%$, dan pendapatan responden yang terbanyak adalah kurang dari Rp. 1.500 .000 dalam sebulan $(58,82 \%)$. 
Untuk status perkawinan adalah yang bujangan $(69,32 \%)$ serta dari segi pekerjaan adalah para pelajar/mahasiswa (46,63\%). Untuk lama menjadi pelanggan yang terbesar ialah lebih dari tujuh bulan $(55,04 \%)$.

Untuk usia responden yang terbesar adalah yang berumur antara 21 sampai dengan 30 tahun yaitu $64,27 \%$, dan pendapatan responden yang terbanyak adalah kurang dari Rp. 1.500 .000 dalam sebulan $(58,82 \%)$. Untuk status perkawinan adalah yang bujangan (69,32\%) serta dari segi pekerjaan adalah para pelajar/mahasiswa (46,63\%). Untuk lama menjadi pelanggan yang terbesar ialah lebih dari tujuh bulan $(55,04 \%)$.

Berdasarkan karakteristik sampel pada tabel 2 diperoleh gambaran (profil) pelanggan salon kecantikan pada umumnya ialah perempuan yang berstatus belum menikah (bujangan), usia pelanggan terbesar berkisar antara 21 sampai dengan 30 tahun terutama dari kalangan mahasiswa; dan pelanggan salon kecantikan umumnya adalah pelanggan yang setia.

\section{Analisis Pengukuran Instrumen Penelitian}

Selanjutnya adalah pengukuran instrumen penelitian dengan memakai alpha Cronbach dengan patokan nilai yang lebih besar dari 0,70 maka instrumen penelitian dinyatakan terandal (reliability). Hasil pengukuran instrumen penelitian disederhanakan dalam Tabel 3.

Tabel 3.

\section{Hasil Pengujian Keterandalan dan Kesahihan Instrumen}

\begin{tabular}{lc}
\hline Variabel & Alpha Cronbach \\
\hline 1. Kualitas Jasa & 0.61 \\
2. Loyalitas advokasi & 0.79 \\
3. Loyalitas membeli kembali (repurchase) & 0.72 \\
4. Loyalitas paymore & 0.78 \\
5. Komitmen afeksi & 0.66 \\
6. Komitmen kontinum & 0.85 \\
7. Komitmen normatif & 0.65
\end{tabular}

Sumber: Diolah dari data primer penelitian.

Setiap variabel diukur masing-masing dengan 3 item (butir) pertanyaan atau pernyataan yang menunjukkan intensitas sikap pelanggan atas kualitas jasa yang diberikan salon langganannya, sikap loyalitas pelanggan dari segi advokasi, tetap menjadi pelanggan dan kesediaan untuk membayar lebih mahal sepanjang masuk diakal pelanggan. Terakhir adalah sikap pelanggan atas komitmennya dari segi afeksi, kesinambungan dan normatif. 
Hasil pengujian di atas memperlihatkan hanya variabel advokasi, membeli ulang, paymore dan komitmen kontinum memperoleh koefisien keterandalan dan kesahihan lebih tinggi dari standar yang ditetapkan. Pada variabel kualitas jasa, komitmen afeksi dan komitmen normatif nilai koefisien untuk keterandalan kurang dari patokan, tetapi koefisien kesahihan lebih besar dari standar minimal. Dengan demikian secara keseluruhan instrumen ini tetap dapat digunakan sekalipun dari segi keterandalan nilai koefisiennya masih dalam kategori marginal.

\section{Pengujian Hipotesis Hubungan antara Variabel dan Loyalitas sebagai Variabel Mediator}

Berikut ini adalah pengujian hubungan antara variabel dan pengujian loyalitas sebagai variabel mediator antara kualitas jasa dan komitmen maupun perbedaan antara kelompok gerai yang disederhanakan dalam Tabel 5 hingga Tabel 7.

Tabel 5.

Korelasi Matrik antar Variabel

\begin{tabular}{|c|c|c|c|c|c|c|c|c|c|c|c|}
\hline & $\mathrm{KJ} 1$ & $\mathrm{KJ} 2$ & $\mathrm{KJ} 3$ & $A D$ & RE & PAY & Afeksi & Kontinum & Normatif & Mean & SD. \\
\hline$\overline{\mathrm{KJ} 1}$ & 1 & & & & & & & & & 5,824 & 1,130 \\
\hline $\mathrm{KJ} 2$ & 0,496 & 1 & & & & & & & & 5,500 & 1,197 \\
\hline KJ3 & 0,260 & 0,285 & 1 & & & & & & & 5,546 & 1,261 \\
\hline$A D$ & 0,207 & 0,181 & 0,071 & 1 & & & & & & 4,602 & 0,838 \\
\hline RE & 0,310 & 0,097 & 0,083 & 0,399 & 1 & & & & & 4,587 & 0,765 \\
\hline PAY & 0,218 & 0,187 & 0,103 & 0,207 & 0,302 & 1 & & & & 4,598 & 0,805 \\
\hline Afeksi & 0,379 & 0,370 & 0,234 & 0,300 & 0,262 & 0,295 & 1 & & & 5,228 & 1,027 \\
\hline Kontinum & 0,113 & 0,215 & 0,200 & 0,200 & 0,216 & 0,243 & 0,428 & 1 & & 3,702 & 1,203 \\
\hline Normatif & $-0,126$ & $-0,198$ & $-0,008$ & 0,048 & 0,048 & 0,105 & $-0,127$ & 0,005 & 1 & 2,992 & 1,045 \\
\hline
\end{tabular}

Sumber: Diolah dari data primer penelitian.

\section{a. Hubungan Kualitas Jasa dengan Loyalitas.}

Hipotesis pertama $(\mathrm{H} 1)$ sampai dengan hipotesis ketiga $(\mathrm{H} 3)$ menyatakan bahwa terdapat hubungan yang positif antara kualitas jasa dengan loyalitas advokasi. loyalitas "repurchase", dan loyalitas "paymore". Rujukan hipotesis ini berdasarkan tesis yang dikemukakan oleh Eagly \& Chaiken (1993) serta lacobucci (1998) dalam penelitian mereka.

Hasil pengujian dengan koefisien korelasi Pearson memperlihatkan angka 0,200 ( $p<0,001), 0,212(p<0,001)$ dan 0,223 ( $p<0,001)$ yang memberikan indikasi ada hubungan yang positif antara keempat variabel ini. Dengan demikian pernyataan hipotesis pertama sampai dengan 
ketiga diterima yang mengemukakan bahwa ada hubungan yang positif antara kualitas jasa dengan loyalitas advokasi loyalitas "repurchase", dan loyalitas "paymore" sebagaimana dengan pendapat yang dikemukakan oleh Eagly \& Chaiken (1993) serta lacobucci (1998).

\section{b. Hubungan Kualitas Jasa dengan Komitmen.}

Hipotesis keempat $(\mathrm{H} 4)$ sampai dengan keenam $(\mathrm{H} 6)$ menyatakan bahwa terdapat hubungan yang positif antara kualitas jasa dengan komitmen afeksi, komitmen kontinum dan komitmen normatif. Rujukan hipotesis ini berdasarkan tesis yang dikemukakan oleh Garbarino dan Johnson (1999) serta Fourier dan Yao (1998) dalam penelitian mereka.

Hasil pengujian dengan koefisien korelasi Pearson memperlihatkan angka 0,433 ( $p<0,001)$ dan 0,237 ( $p<0.001)$ yang memberikan indikasi ada hubungan yang positif antara ketiga variabel ini. Dengan demikian pernyataan hipotesis keempat sampai dengan keenam diterima yang mengemukakan bahwa ada hubungan yang positif antara kualitas jasa dengan komitmen afeksi dan komitmen kontinum sebagaimana dengan pendapat yang dikemukakan oleh Garbarino dan Johnson (1999) serta Fourier dan Yao (1998). Sementara untuk pengujian hubungan antara kualitas jasa dengan komitmen normatif memperlihatkan angka - ,145 $(p<0,05)$ yang memberikan indikasi ada hubungan yang negatif antara variabel ini. Dengan demikian hasil ini berbeda dengan pendapat yang dikemukakan oleh Garbarino dan Johnson (1999) serta Fourier dan Yao (1998). Lemahnya hubungan loyalitas dengan komitmen normatif cukup masuk akal karena di Indonesia, salon kecantikan seperti halnya bengkel mobil adalah beberapa industri yang termasuk industri jasa yang tidak terlalu menekankan loyalitas advocacy sebagai landasan komitmen ini (Jasfar,1998).

\section{c. Hubungan Loyalitas Advokasi dengan Komitmen.}

Hipotesis ketujuh (H7) sampai dengan kesembilan (H9) menyatakan bahwa terdapat hubungan yang positif antara loyalitas advokasi dengan komitmen afeksi, komitmen kontinum dan komitmen normatif. Rujukan hipotesis ini berdasarkan penelitian yang dilakukan oleh Morgan dan Hunt (1994), Doney dan Cannon (1997) serta Garbarino dan Johnson (1999).

Hasil pengujian dengan koefisien korelasi Pearson memperlihatkan angka 0,300 ( $p<0,001)$ dan 0,200 ( $p<0.01)$ yang memberikan indikasi ada hubungan yang positif antara variabel ini. Dengan demikian pernyataan hipotesis ketujuh dan kedelapan dapat diterima yang mengemukakan bahwa ada hubungan yang positif antara loyalitas advokasi dengan komitmen afeksi dan komitmen kontinum sebagaimana dengan pendapat yang dikemukakan oleh Morgan dan Hunt (1994), Doney dan Cannon (1997) serta Garbarino dan Johnson (1999). 
Hasil pengujian yang berbeda antara loyalitas advokasi dengan komitmen normatif memperlihatkan angka 0,048 ( $p>0,10)$ yang memberikan indikasi ada hubungan yang positif tetapi sangat lemah antara variabel ini. Dengan demikian pernyataan hipotesis kesembilan yang mengemukakan bahwa ada hubungan yang positif antara loyalitas advokasi dengan komitmen normatif terbukti walaupun hubungannya sangat lemah. Pada jenis komitmen ini umumnya responden memperlihatkan sikap ragu ragu, bahkan dalam hal ini bersikap negatif.

\section{d. Hubungan Loyalitas "Repurchase" dengan Komitmen.}

Hipotesis kesepuluh ( $\mathrm{H} 10)$ sampai dengan keduabelas ( $\mathrm{H} 12)$ menyatakan bahwa terdapat hubungan yang positif antara loyalitas "repurchase" dengan komitmen afeksi komitmen kontinum dan komitmen normatif. Rujukan hipotesis ini berdasarkan tesis yang dikemukakan oleh Allen dan Meyer (1990) serta Fullerton dan Taylor (2000) dalam penelitian mereka.

Hasil pengujian dengan koefisien korelasi Pearson memperlihatkan angka 0,262 ( $p<0,001)$ dan 0,216 ( $<<0.01)$ yang memberikan indikasi ada hubungan yang positif antara ketiga variabel ini. Dengan demikian pernyataan hipotesis kesepuluh hingga kesebelas dapat diterima yang mengemukakan bahwa ada hubungan yang positif antara loyalitas "repurchase" dengan komitmen afeksi sebagaimana dengan pendapat yang dikemukakan oleh Allen dan Meyer (1990) serta Fullerton dan Taylor (2000).

Hasil pengujian mengenai hubungan loyalitas "repurchase" dengan komitmen normatif memperlihatkan angka 0,007 ( $p>0,10)$ yang memberikan indikasi ada hubungan yang positif. Dengan demikian pernyataan hipotesis keduabelas yang mengemukakan bahwa ada hubungan yang positif antara loyalitas "repurchase" dengan komitmen normatif dapat diterima meskipun sangat lemah. Jadi hasilnya agak berbeda dengan pendapat yang dikemukakan oleh Allen dan Meyer (1990) serta Fullerton dan Taylor (2000). Sama halnya dengan komentar kami sebelumnya, hal ini disebabkan karena konsumen salon kecantikan tidak terlalu mementingkan komitmen normatif sebagai alat untuk mempertahankan hubungan jangka panjang (loyalitas).

\section{e. Hubungan Loyalitas "Paymore" dengan Komitmen.}

Hipotesis tiga belas (H13) sampai dengan lima belas ( $\mathrm{H} 15)$ menyatakan bahwa terdapat hubungan yang positif antara loyalitas "paymore" dengan komitmen afeksi, komitmen kontinum dan komitmen normatif. Rujukan hipotesis ini berdasarkan tesis yang dikemukakan oleh Allen dan Meyer (1990) serta Fullerton dan Taylor (2000) dalam penelitian mereka. 
Hasil pengujian dengan koefisien korelasi Pearson memperlihatkan angka $0,295(p<0,001)$ dan 0,243 ( $p<0.001)$ yang memberikan indikasi ada hubungan yang positif antara kedua variabel ini. Dengan demikian pernyataan hipotesis ketigabelas dan empat belas dapat diterima yang mengemukakan bahwa ada hubungan yang positif antara loyalitas "paymore" dengan komitmen afeksi dan komitmen kontinum sebagaimana dengan pendapat yang dikemukakan oleh Allen dan Meyer (1990) serta Fullerton dan Taylor (2000).

Hasil pengujian yang berbeda terlihat antara loyalitas "paymore" dengan komitmen normatif yang memperlihatkan angka 0,105 $(p>0,10)$ yang memberikan indikasi ada nya hubungan yang positif tetapi sangat lemah antara variabel ini. Dengan demikian pernyataan hipotesis kelimabelas dapat diterima yang mengemukakan bahwa ada hubungan yang antara loyalitas "paymore" dengan komitmen normatif walaupun sangat lemah. Jadi hasilnya berbeda dengan pendapat yang dikemukakan oleh Allen dan Meyer (1990) serta Fullerton dan Taylor (2000). Lemahnya komitmen normatif dengan kualitas jasa maupun loyalitas seperti hasil-hasil pengujian di atas cukup masuk akal, karena salon kecantikan seperti bengkel mobil, yang termasuk dalam industri jasa yang sebenarnya tidak terlalu membutuhkan hubungan jangka panjang menjadi hal yang teramat penting (Jasfar, 1998).

f. Perbedaan Kualitas Jasa, Loyalitas dan Komitmen dari segi Gerai

Adanya perbedaan ini dapat ditelusuri dari pengelompokkan pelanggan yang memakai jasa salon kecantikan pada pusat perbelanjaan modern dengan kategori pelanggan yang termasuk dalam shopping strips. Pembagian kelompok pelanggan berdasarkan penelitian yang dilakukan oleh Garbarino dan Johnson (1999) serta Brown dan Tax: 1994).

Hasil pengujian rata-rata antara kelompok gerai 1 dan kelompok gerai 2 salon kecantikan atas kualitas jasa, loyalitas dan komitmen yang memperlihatkan adanya perbedaan ialah loyalitas membeli kembali mendapat nilai t $1.899(p<0,10)$. loyalitas "paymore" mendapat nilai t $2.150(p<0,05)$, komitmen afeksi mendapat nilai t $2.898(p<0,05)$, komitmen normatif mendapat nilai t $2.883(p<0,10)$. Selebihnya menunjukkan adanya perbedaan antara kedua kelompok gerai tersebut seperti diperlihatkan dalam Tabel 5.

Kualitas jasa, loyalitas advokasi dan komitmen kontinum yang tidak berbeda antara kedua kelompok gerai tersebut memberikan indikasi bahwa salon kecantikan yang termasuk dalam kategori shopping stripes terus meningkatkan kemampuan bersaingnya untuk mencegah larinya pelanggan ke salon kecantikan lainnya. 


\section{g. Loyalitas sebagai Mediator antara Kualitas Jasa dan Komitmen}

Hipotesis ketujuhbelas menyatakan bahwa loyalitas merupakan variabel mediator antara kualitas jasa dan komitmen yang disusun berdasarkan penelitian dari Fullerton dan Taylor (2000). Pada pengujian loyalitas sebagai variabel mediator memberikan hasil yang cukup memuaskan dimana bila kualitas jasa berpengaruh langsung terhadap komitmen maka estimasi parameter hanya mendapat koefisien sebesar 0,294, tetapi bila melalui loyalitas maka akan menjadi lebih besar estimasi parameternya yaitu sebesar 0,708 (Tabel 7).

Sekalipun demikian untuk pengujian model hipotesis tersebut masih diperlukan beberapa pengujian dari segi Absolute Fit Measures (AFM), Incremental Fit Measures (IFM), dan Parsimonious Fit Measures sebagaimana akan dipaparkan berikut ini.

Hasil pengujian dengan SEM (Structural Equation Modeling) mendapatkan nilai X2 31.902 pada derajat kebebasan $17(\mathrm{p}<0,05)$ yang menunjukkan bahwa loyalitas memiliki hubungan sebagai variabel mediator antara kualitas jasa dan komitmen untuk Goodness of Fit Index (GFI) mendapat nilai 0,968 yang berarti lebih besar dari nilai untuk ukuran yaitu lebih besar 0,90 . Untuk RMSEA standardized residual diperoleh 0,015 . Nilai residual yang direkomendasi adalah semakin mendekati angka 0 semakin baik. Berarti model loyalitas sebagai variabel mediator antara kualitas jasa dan komitmen dari segi AFM diterima dengan meyakinkan (signifikansi).

Selanjutnya dari segi Incremental Fit Measures (IFM) digunakan ukuran AGFI dan Normed Fit Index dengan masing-masing nilai 0,934 dan 0,905 untuk diterima atau ditolak model yang diuji adalah yang mendapat nilai lebih besar dari 0,90 yang berarti dari kriteria IFM loyalitas sebagai variabel mediator antara kualitas jasa dengan komitmen dapat diterima secara signifikan. Hanya saja dari pengukuran kesederhanaan (Parsimonious) model belum memberikan hasil yang meyakinkan karena nilai PNFI hasilnya sebesar 0,549, sebab semakin kecil nilai PNFI semakin baik.

Hasil secara keseluruhan pengujian model ditampilkan dalam Gambar 2 dengan koefisien parameter untuk setiap sub-variabel maupun masing-masing variabel kualitas jasa, loyalitas dan komitmen. Dalam pengujian yang ditampilkan tersebut terlihat bahwa sub-variabel komitmen normatif tidak signifikan, sehingga untuk industri jasa di Indonesia pada tingkat komitmen yang relevan adalah komitmen afeksi dan komitmen kontinum. 
Tabel 6.

Perbedaan Kualitas Jasa, Loyalitas dan Komitmen dari segi Gerai

\begin{tabular}{l|ccccc}
\hline \multicolumn{1}{c|}{ Variabel } & $\begin{array}{c}\text { Mean } \\
\text { Gerai 1 }\end{array}$ & $\begin{array}{c}\text { Mean } \\
\text { Gerai 2 }\end{array}$ & t-value & Df & P \\
\hline Kualitas Jasa & 5,600 & 5,643 & $-0,370$ & 236 & 0,712 \\
Loyalitas advokasi & 4,588 & 4,615 & $-0,245$ & 236 & 0,807 \\
Loyalitas membeli kembali (repurchase) & 4,688 & 4,500 & 1,899 & 236 & 0,059 \\
Loyalitas Paymore & 4,718 & 4,495 & 2,150 & 236 & 0,033 \\
Komitmen afeksi & 5,433 & 5,052 & 2,898 & 236 & 0,004 \\
Komitmen kontinum & 3,676 & 3,724 & $-0,308$ & 236 & 0,759 \\
Komitmen normative & 3,118 & 2,883 & 1,739 & 236 & 0,083 \\
\hline
\end{tabular}

Sumber: Diolah dari data penelitian.

Tabel 7.

Estimasi Parameter Hasil Pengujian Hipotesis dengan SEM (Structural Equation Model)

\begin{tabular}{|c|c|c|c|}
\hline Regression Weights & Estimate & S.E. & C.R. \\
\hline Loyalitas <----------- KJ & 0.294 & 0.072 & 4.059 \\
\hline Komitmen <------- Loyalitas & 0.708 & 0.219 & 3.225 \\
\hline Komitmen <--------- KJ & 0.458 & 0.121 & 3.793 \\
\hline \multicolumn{4}{|l|}{ Measures of Absolute Fit } \\
\hline Chi-square & & 31.902 & \\
\hline Degrees of freedom & & 17 & \\
\hline Probability level & & 0.015 & \\
\hline NCP (Noncentrality Parameters) & & 14.902 & \\
\hline GFI (Goodness-of-Fit Index) & & 0.969 & \\
\hline RMSEA (Root Mean Square Error of Approximation) & & 0.061 & \\
\hline \multicolumn{4}{|l|}{ Incremental Fit Measures } \\
\hline AGFI (Adjusted Goodness-of-Fit Index) & & 0.934 & \\
\hline TLI (Tucker-Lewis Index) & & 0.920 & \\
\hline NFI (Normed Fit Index) & & 0.905 & \\
\hline \multicolumn{4}{|l|}{ Parsimonious Fit Measures } \\
\hline PNFI (Parsimonious Normed Fit Index) & & 0.549 & \\
\hline PGFI (Parsimonious Goodness-of-Fit Index) & & 0.458 & \\
\hline
\end{tabular}




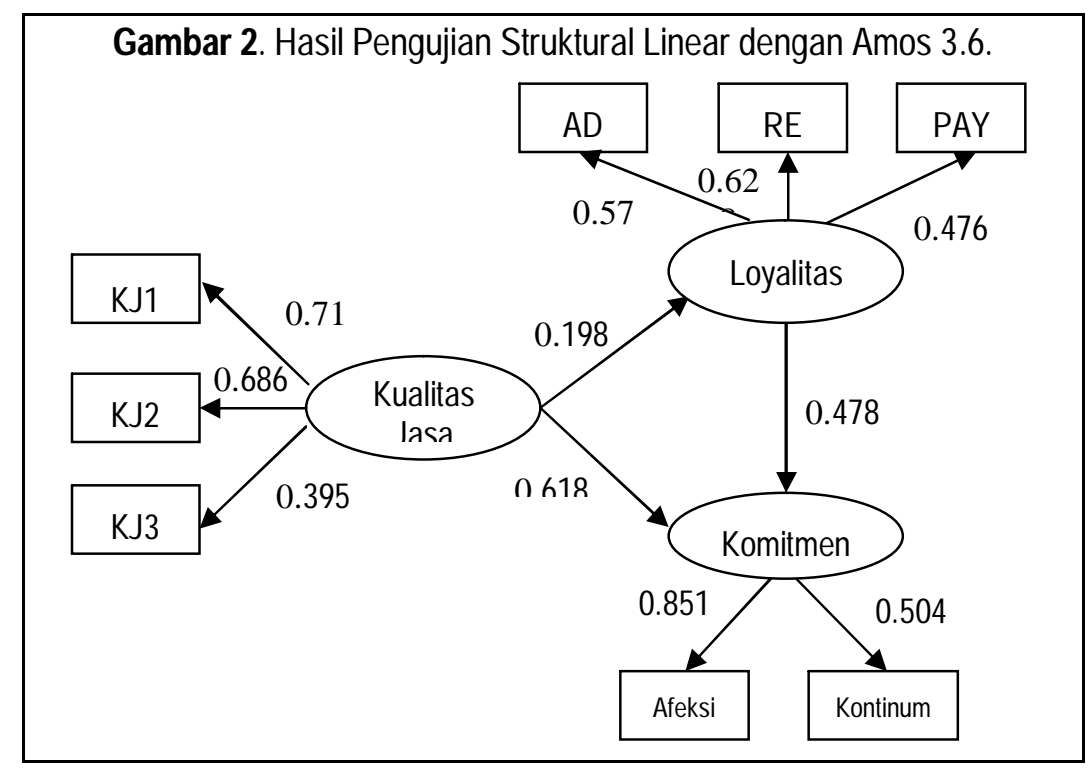

\section{PEMBAHASAN DAN DISKUSI}

Hasil yang diperoleh dari segi profil salon, umumnya salon kecantikan yang berpusat pada regional shopping center dan community shopping center, lebih efektif dalam menjaring pelanggan. Dari segi pemasaran jasa, pilihan saluran distribusi pada dua jenis saluran ini nampaknya cukup efektif oleh karena "nama-nama besar" dalam dunia salon kecantikan memiliki kiprah yang cukup meyakinkan dari segi ekspansi gerai yang dibuka.

Namun dari segi profil responden terlihat bahwa salon kecantikan belum memfokuskan segmentasi pelanggan secara baik, terlihat bahwa pelanggan utama salon kecantikan memiliki ciri adalah perempuan yang belum berkeluarga dan berusia antara 21 sampai dengan 30 tahun. Banyak interpretasi atas fenomena ini antara lain:

- Kemungkinan kesalahan dalam pengambilan sampel, sekalipun tingkat kesalahan responden adalah 3\%, karena tenaga pewawancara adalah dari kalangan usia tersebut.

- Perempuan muda lebih membutuhkan jasa salon kecantikan untuk meningkatkan rasa percaya diri.

- Perempuan berkeluarga entah karena faktor kesibukan atau faktor lainnya belum memanfaatkan secara maksimal jasa salon kecantikan. Ada kemungkinan, yang masih perlu diteliti lebih lanjut perempuan berkeluarga hanya menggunakan jasa salon kecantikan untuk keperluan tertentu saja, 
misalnya potong rambut saja atau penataan rambut untuk keperluan resepsi (pernikahan) semata.

Melihat kenyataan seperti ini bisnis salon kecantikan adalah bisnis yang masih memberikan peluang usaha yang luar biasa, karena banyak segmen pasar yang belum tersentuh, misalnya saja dari kalangan pria, wanita karir dan ibu rumah tangga, yang secara ekonomi memiliki daya beli (purchasing power) yang baik.

Dari tiga variabel utama yaitu kualitas jasa, loyalitas dan komitmen, maka hanya pada variabel komitmen saja responden memperlihatkan hasil yang agak berbeda, terutama pada komitmen kontinum dan komitmen normatif. Pada kedua jenis komitmen ini umumnya responden memperlihatkan sikap negatif atau agak ragu-ragu terhadap salon kecantikan. Pada pengujian hipotesis, terutama hubungan antar variabel, maka komitmen normatif tidak memiliki hubungan yang signifikan dengan ketiga jenis loyalitas. Bahkan dengan kualitas jasa terdapat hubungan dengan arah negatif sekalipun cukup signifikan.

Pada uji rata-rata antara kelompok gerai 1 dan gerai 2 terlihat dari segi kualitas jasa, loyalitas advokasi dan komitmen kontinum tidak ada perbedaan antara kedua kelompok gerai tersebut. Hal ini berarti kualitas jasa layanan, loyalitas advokasi dan komitmen kontinum pelanggan antara salon kecantikan yang berpusat pada mal maupun di pinggiran kota serta permukiman penduduk nyaris sama baiknya. Perbedaan baru terlihat pada loyalitas membeli kembali, membayar lebih, dan komitmen afeksi serta komitmen normatif diantara salon kecantikan yang berpusat di mal atau pusat perbelanjaan lainnya lebih unggul dibandingkan dengan kelompok gerai dipinggiran kota dan dipermukiman penduduk.

Pada pengujian loyalitas sebagai variabel mediator memberikan hasil yang cukup memuaskan di mana kualitas jasa berpengaruh langsung terhadap komitmen dilihat dari measures of absolute fit, incremental fit measures dan parsimonious fit measures.

\section{KESIMPULAN}

Kualitas jasa memiliki hubungan positif dengan loyalitas, komitmen afeksi dan komitmen kontinum, tetapi memiliki hubungan yang negatif dengan komitmen normatif. Hal ini tidak terlalu mengherankan oleh karena, hubungan pelanggan dengan salon kecantikan berbeda dengan industri jasa lain seperti perbankan, asuransi atau lembaga pendidikan yang didasarkan hubungan jangka panjang dan berdasarkan kepercayaan yang kuat dari pelanggan terhadap perusahaan atau organisasi.

Kualitas jasa, loyalitas advokasi dan komitmen kontinum tidak berbeda antara salon kecantikan yang berada di pusat-pusat perbelanjaan 
dengan salon kecantikan yang berada di pinggiran kota dan dekat dengan permukiman penduduk. Perbedaan terjadi pada loyalitas membeli kembali, loyalitas "paymore" komitmen afeksi dan komitmen normatif.

Loyalitas sebagai mediator antara kualitas jasa dengan komitmen terbukti secara meyakinkan dilihat dari tiga ukuran pengujian model dari SEM (Structural Equation Modeling) yaitu measures of absolute fit, incremental fit measures dan parsimonious fit measures.

\section{IMPLIKASI DAN PENELITIAN LANJUTAN (FUTURE RESEARCH)}

Implikasi yang paling terlihat secara teoritis ialah komitmen pada tingkat normatif mungkin masih terlalu abstrak (ideal) untuk dapat dicerna atau dipahami oleh pelanggan di Indonesia. Dalam derajat tertentu pelanggan masih terfokus pada harga dan kualitas pelayanan. Sementara implikasi pada tingkat terapan, pengelola salon kecantikan perlu memperluas strategi pemasaran dari segi segmentasi. Kalangan pria, wanita karir dan ibu rumah tangga adalah segmen pasar yang tidak boleh diabaikan begitu saja, terutama dari segi daya beli dan aksesibilitas. Perlu keseimbangan antara strategi perluasan pasar (pembukaan gerai pada pusat-pusat perbelanjaan) dengan strategi segmentasi yang jitu. Dengan kata lain pengusaha salon kecantikan agar lebih "market oriented."

Penelitian lanjutan dapat dilakukan terhadap salon kecantikan itu sendiri sebagai satuan analisis maupun variabel-variabel lain yang perlu diteliti seperti faktor tangible dari jasa salon kecantikan, empati dan kualitas hubungan (quality relationship) antara pelanggan dan manajemen salon kecantikan.

\section{DAFTAR PUSTAKA}

Babbacus, E., and G.W. Boller (1992), "An Empirical Assessment of the SERVQUAL Scale," Journal of Business Research, 24. p. 253-268.

Bagozzi, Richard P (1995), "Reflections on Relationship Marketing in Consumer Markets", Journal of the Academy of Marketing Science, 23 (4).

Bendapudi, Neeli and Leonard L. Berry (1997), "Customers' Motivations for Maintaining Relationships With Service Providers", Journal of Retailing. 73.

Berry, Leonard L., (1983), "Relationship Marketing," in Emerging Perspectives on Services Marketing, L. Berry, G.L. Shostack, and G.D. Upah, eds., Chicago: American Marketing Association, p. 25-28. 
\& A. Parasuraman. (1991), Marketing Services, New York: The Free Press.

., (1983), "Relationship Marketing," in Emerging Perspectives on Services Marketing, L. Berry, G.L. Shostack, and G.D. Upah, eds., Chicago: American Marketing Association, p. 25-28.

., A. Parasuraman, Zeithaml, Valerie A (1994), "Improving Service Quality in America: Lessons Learned," Academy of Management Executive, Vol. 8, No. 2, p. 32-45.

Brown, T.J., G.A. Churchill \& J.P. Peter (1993), "Improving The Measurement of Service Quality," Journal of Retailing No.69 (1, Spring). p.127-139.

Carman, J.M. (1990), "Consumer Perceptions of Service Quality an Assessment of the SERVQUAL Dimensions," Journal of Retailing No.66 (1, Spring). p.33-35.

Cronin, J. Joseph Jr and Steven A. Taylor (1992). Measuring Service Quality: A Reexamination and Extension. Journal of Marketing, 56 (July). p.68-81.

(1994), "SERVPERF versus SERVQUAL: Reconciling Perfor-mance Based \& Perceptions Minus Expectations Measurement of Services Quality," Journal of Marketing No.58, January, p. 125-131.

Dwyer, F. Robert., Paul H. Schurr, \& Sejo Oh, (1987), "Developing BuyerSeller Relationship", Journal of Marketing, Vol. 51 (April), p.11-27.

Freeman, K.D. \& J. Dart (1993), ":Measuring the Perceived Quality of Professional Business Services," Journal of Professional Services Marketing No.9 (1). p.127-131.

Fullerton, Gordon \& Shirley Taylor (2000)., The Role of Commitment in Service Relationship, Kingston, Ontario: School of Business Acadia University, limited publication. p.3-18

Garbarino, Ellen \& Mark S. Johnson. (1999), The Different Roles of Satisfaction, Trust and Commitment in Customer Relationships. Journal of Marketing Vol. 63 (April). p. 83-97.

Gundlach, Gregory T., Ravi S. Acrol \& John T. Mentzer (1995). The Structure of Commitment in Exchange. Journal of Marketing, 1995 (January). p. 78-92.

Heide, Jan B \& John, George (1992), "Do Norms Matter in Marketing Relationship?", Journal of Marketing, No. 56 (April), p.32-44. 
Jasfar, Farida (1998)., Faktor-faktor yang Mempengaruhi Pelanggan dalam Memilih Bengkel Mobil (Service Station), Jakarta: Fakultas Ekonomi Universitas Trisakti.

., (1999)., Analisis Kualitas Jasa pada Perusahaan Solution Provider, Jakarta: Fakultas Ekonomi Universitas Trisakti

., (2000)., Analisis Kualitas Kemitraan antara Perusahaan Dealer Mobil dengan Perusahaan Otomotif, Media Ekonomi, Volume 6, Nomor 2, Agustus, 778-798, Jakarta

Kotler, Philip (1998)., Marketing Management: Analysis, Planning, Implementation and Control, Chicago, Illinois: Prentice Hall

Lapierre, Jozee (1996)., Service Quality: The Construct, Its Dimensionality \& Its Measurement, Services Marketing and Management, Volume 5.

Moorman, Christine, Gerald Zaltman \& Rohit Deshpande (1992), "Relationships Between Providers and User of Marketing Research: The Dynamics of Trust Within and Between Organization," Journal of Marketing Research, 29 (August), p.314-329.

Morgan, Robert M. \& Shelby D. Hunt (1994), "The Commitment Trust Theory of Relationship Marketing" Journal of Marketing, July. p. 20-38.

Parasuraman, A., Valerie A. Zeithaml and Leonard L. Berry (1994). Reassessment of Expectations as a Comparison Standard in Measuring Service Quality: Implications for Further Research. Journal of Marketing, 58 (January). p. 32-45.

Rust, Roland T., Anthony J. Zahorik \& Timothy L. Keiningham (1995), "Return on Quality (ROQ): Making Service Quality Financially Accountable," Journal of Marketing, 59 (April). p.83-97.

Zeithmal, Valerie A., Leonard L. Berry \& A. Parasuraman (1996). Behavioral Consequences of Service Quality. Journal of Marketing, 60 (April). p. 70-87. 